\title{
Awareness of emergency contraception: a follow-up report
}

\author{
Melanie Fitter, Rennie Urquhart
}

\begin{abstract}
Background and methodology This study aimed to ascertain whether recent campaigns aimed at increasing awareness and use of progestogen-only emergency contraception (POEC) have been effective, by comparing the understanding and awareness of POEC in those attending the termination of pregnancy (TOP) clinic in 2006 to an earlier cohort studied in 2003. Questionnaires were handed to all women attending the TOP clinic during a 4-week period in September/October 2006. Questionnaires were collected before women left the clinic.
\end{abstract}

Results All women $(n=77)$ attending the clinic received questionnaires; 72 were returned. Most (96\%) of the women were familiar with POEC, compared with $78 \%$ of the 2003 cohort. $79 \%$ of the women felt confident about the ease of availability of POEC compared to $60 \%$ in 2003. More (51\%) had used POEC in the past compared with $37 \%$ of the 2003 group. Only $46 \%$ knew the correct

\section{Introduction}

Emergency contraception (EC) is a form of contraception used to prevent pregnancy after unprotected intercourse. The present methods of EC available for use in the UK are single-dose progestogen-only emergency contraception (POEC) and the copper intrauterine device (IUD).

Increasing awareness of and access to EC is one critical way to improve the health of women by preventing unintended pregnancy and abortion. In the past 5 years, a number of international organisations, including the World Health Organization, have worked to make EC more widely available and to increase knowledge about this method among both providers and consumers.

These campaigns resulted in POEC being made available for purchase off-prescription from pharmacies in the UK. More specific campaigns, such as EC72, which was launched in Lothian in Scotland in June 2003, aimed to provide free POEC to women aged between 14 and 25 years in areas characterised by high levels of deprivation or where there is a lack of alternative sources of POEC.

This study aimed to ascertain whether the campaigns and new policies on availability of POEC have been effective by comparing the understanding and awareness of POEC in those attending the termination of pregnancy (TOP) clinic in Fife during September and October 2006 to an earlier cohort of women studied in February 2003.1

\section{Methods}

A questionnaire was handed out to all women attending the Community Gynaecology (TOP) clinic in Forth Park Hospital, Kirkcaldy, which serves a population of around

Community Gynaecology Clinic, Forth Park Hospital, Kirkcaldy, UK

Melanie Fitter, MBChB, GP Specialty Trainee

Rennie Urquhart, MBChB, FRCOG, Consultant

Correspondence to: Dr Melanie Fitter, Community Gynaecology Clinic, Forth Park Hospital, 30 Bennochy Road, Kirkcaldy KY2 5RA, UK. E-mail: melfitter@doctors.org.uk time limit for effectiveness of POEC compared to $59 \%$ in 2003. Time limit awareness was lower among the 16-20year-old age group compared to the 21-25-year-old group. Most respondents $(89 \%)$ said that they would consider using POEC in the future.

Discussion and conclusions Awareness and use of POEC have improved since 2003 but accurate knowledge has not. There is confusion regarding the correct time limit for effectiveness of POEC, especially amongst the 16-20year-old age group. Public awareness campaigns appear to have been effective in increasing awareness and availability of POEC in Fife, Scotland. More emphasis is needed on the appropriate and effective use of POEC, especially targeted to the 16-20-year-old age group.

Keywords education techniques, emergency contraception, POEC, public awareness

J Fam Plann Reprod Health Care 2008; 34(2): 111-113

(Accepted 4 May 2007))

\section{Key message points}

- More effective tailored education training targeted at the 16-20-year-old age group is required, perhaps through school-based sex education, media campaigns and in the primary care setting.

- There is a need to continue to emphasise contraception methods, especially long-term methods.

- Use of the term 'morning-after pill' needs to be phased out since this term may be confusing women regarding the time limit for effectiveness of progestogen-only emergency contraception.

300000 . The questionnaire was based on the original study questionnaire from February 2003. Questionnaires were handed out at the reception on arrival and collected before the women left the clinic for four consecutive weeks in September and October 2006. The data were analysed using SPSS v.15.0 (SPSS Inc., Chicago, IL, USA).

\section{Ethical approval}

As this study was based on an anonymous questionnaire, there were no consent issues and ethical committee clearance was not required.

\section{Results}

All the women $(n=77)$ attending the TOP clinic were asked to complete a questionnaire. Of the 77 questionnaires handed out at the TOP clinic, 72 were completed and returned but 13 women did not disclose their age. The age range of the women who fully completed questionnaires was 14 to 48 years, with the median age being 22 years. Age was split into six groups for preliminary analysis: the modal age category was 16-20 years (Figure 1).

\section{Past use of contraception and EC}

Thirty-seven $(51 \%)$ of the women questioned had used POEC in the past. Eighteen $(25 \%)$ women had undergone a previous TOP. Forty-seven $(65 \%)$ women were using contraception prior to becoming pregnant on this occasion. The most popular forms of contraception amongst these women were the combined contraceptive pill and condoms. 


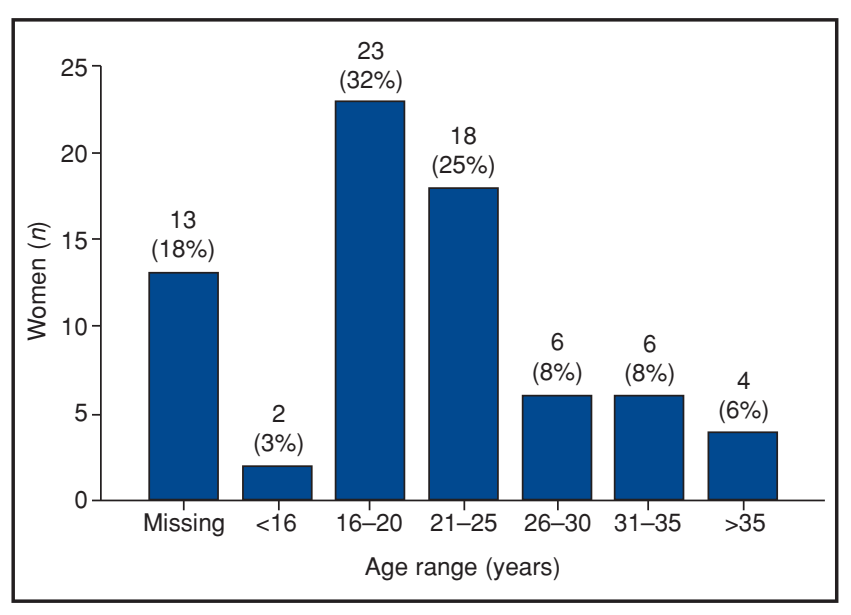

Figure 1 Age range of women in the study

\section{Familiarity with and current use of EC}

Sixty-nine $(96 \%)$ women were familiar with the term 'emergency contraception' or the 'morning-after pill'. The majority of the women could list at least two sources of POEC: 29 (40\%) listed chemists/pharmacy, 37 (51\%) listed doctors/general practitioner (GP), 22 (31\%) listed family planning clinics, eight (11\%) listed other sources (e.g. genitourinary clinic, accident and emergency department) and only two (3\%) did not know of any sources. Fiftyseven $(79 \%)$ women felt that access to POEC was easy or very easy. Despite this apparent high level of familiarity, only 4/72 (6\%) of those questioned had taken POEC during this pregnancy.

Thirty-three $(46 \%)$ women knew that the correct time limit for effectiveness of POEC was 72 hours. Eighteen $(25 \%)$ thought that POEC was effective up to 48 hours after unprotected sexual intercourse (UPSI) (Table 1). Of the 16-20-year-olds, 35\% knew the correct time limit compared to $61 \%$ of the $21-25$-year-olds and $42 \%$ of those aged over 25 years.

\section{Future use of contraception}

Seventy (97\%) women stated that they would use a form of contraception in the future and $64(89 \%)$ would consider using POEC.

\section{Discussion}

In this study the TOP service was mostly used by women aged between 16 and 25 years. More $(96 \%)$ of the women questioned were familiar with POEC than in the 2003 cohort $(78 \%)$ (Table 2). Of those who were aware of POEC, the majority knew where it was available, and the awareness of specific sources of POEC was similar to the 2003 cohort. In addition, more (79\%) of the women felt confident about the ease of availability of POEC than in $2003(60 \%)$. These results concur with those of a similar study in Scotland in $1999,{ }^{2}$ and are an indication of the positive effect of education and awareness policies such as the change in availability and access to POEC brought about in 2001.

Table 1 Knowledge of correct time limit for effectiveness

\begin{tabular}{lcc}
\hline Time limit & Frequency $(\boldsymbol{n})$ & Percentage (\%) \\
\hline$\leq 6$ hours & 2 & 2.8 \\
$\leq 12$ hours & 4 & 5.6 \\
$\leq 24$ hours & 12 & 16.7 \\
$\leq 48$ hours & 18 & 25.0 \\
$\leq 72$ hours & 33 & 45.8 \\
$\leq 1$ week & 2 & 3.8 \\
\hline
\end{tabular}

Table 2 Comparison of awareness of emergency contraception between the 2003 and 2006 cohorts

\begin{tabular}{|c|c|c|}
\hline \multirow[t]{2}{*}{ Parameter } & \multicolumn{2}{|c|}{ Cohort $[n(\%)]$} \\
\hline & $\begin{array}{l}2003 \\
(n=76)\end{array}$ & $\begin{array}{l}2006 \\
(n=72)\end{array}$ \\
\hline Familiar with EC & $59(78)$ & $69(96)$ \\
\hline Believe that $\mathrm{EC}$ is & $46(60)$ & $57(79)$ \\
\hline \multirow{2}{*}{\multicolumn{3}{|c|}{$\begin{array}{l}\text { easily/very easily available } \\
\text { Source of EC }\end{array}$}} \\
\hline & & \\
\hline Doctor/general practitioner & $52(68)$ & $37(51)$ \\
\hline Chemist/pharmacy & $33(43)$ & $29(40)$ \\
\hline Family planning clinic & $15(20)$ & $22(31)$ \\
\hline Other & $26(33)$ & $8(11)$ \\
\hline Don't know & - & $2(3)$ \\
\hline \multirow{4}{*}{$\begin{array}{l}\text { Correct knowledge about } 72 \text {-hour } \\
\text { time limit for effectiveness of EC } \\
\text { Have used EC in the past } \\
\text { EC used in this pregnancy } \\
\text { Would use EC in future }\end{array}$} & $45(59)$ & $33(46)$ \\
\hline & $28(37)$ & $37(51)$ \\
\hline & $4(5)$ & $4(6)$ \\
\hline & $68(90)$ & $64(89)$ \\
\hline
\end{tabular}

EC, emergency contraception.

Roughly half of the women (51\%) questioned had used POEC in the past compared with $37 \%$ of the original 2003 cohort. From this small sample it is impossible to be sure that this change represents a real increase, however the apparent increase in the use of POEC correlates with increasing awareness of POEC and its availability, and also correlates with current trends in the use of POEC in the UK. Between 1990 and 1996, the number of emergency contraceptives prescribed in England more than tripled, with around two-thirds of these being prescribed by GPs. ${ }^{3}$

Although use of POEC seems high, understanding of its effectiveness is less strong and may even have declined since 2003: only $46 \%$ of the women questioned were aware that POEC had to be used within 72 hours of UPSI for it to be effective compared to $59 \%$ in the 2003 cohort. In addition, awareness of the time limit for effectiveness appears to be lower among the 16-20-year-old age group compared to the 21-25-year-old age group. Although effectiveness of POEC declines from $95 \%$ effective if taken less than 12 hours post-UPSI to $58 \%$ for $49-72$ hours post$\mathrm{UPSI}^{4}$ it is still licensed for use up to that time.

These results may reflect increasing knowledge with age; however, the over-25-year-old women appeared to be less informed than the women in the 21-25-year-old age group. This result suggests that there may have been a peak of awareness around the time when the licensing arrangements for POEC were amended in 2001, and the accompanying media attention that this event received. Today's 21-25-year-olds were in the 16-20-year-old age group at that time and likely to be becoming sexually active, and it is possible that they were most influenced by this change in policy, and thus have a higher awareness and knowledge regarding POEC.

Another possible factor influencing women's understanding of the time limit of effectiveness of POEC may be in the commonly used phrase, 'morning-after pill' - a potentially confusing name that perhaps gives the impression that POEC is only suitable for use the morning after UPSI.

Although $96 \%$ of the women were familiar with POEC, and $51 \%$ claimed to have used POEC in the past, only 4/72 women had taken POEC in this current pregnancy, obviously with poor effect. This figure is very similar to that for the 2003 cohort, where 4/76 women had taken POEC in their current pregnancy. These results seem to suggest that although awareness of POEC is quite high, actual uptake and confidence in using POEC appropriately 
and correctly is relatively low. However, many women simply may not have realised that they were at risk of pregnancy and therefore did not recognise the need for POEC. A recent study that examined the impact of giving women a supply of POEC to keep at home showed that although the use of POEC did increase, pregnancy and abortion rates did not change. On closer questioning as to why POEC was not used, three out of four women did not realise that they were at risk of pregnancy. 5,6

Some $25 \%$ of the women attending the TOP clinic had had a previous termination. This figure, which is consistent with the UK trend, suggests that although many women may not realise that they are at risk of pregnancy, education and advice given at the TOP clinic is ineffective in a significant proportion of cases. There are of course other reasons why women may seek a TOP, such as the breakdown of a relationship or lack of pregnancy risk awareness, which are not dependent on contraception failure.

Reassuringly, $97 \%$ of respondents said that they would be using a form of contraception in the future compared to $65 \%$ who were using any prior to becoming pregnant. In addition, as in the 2003 cohort, nine out of ten women would consider using POEC in the future if the need arose. This result suggests that women have a generally positive attitude towards EC, even though the evidence from the present study suggests that women are not necessarily going on to use EC in an appropriate and effective way.

\section{Conclusions}

Both awareness and use of POEC amongst women attending the TOP clinic in Fife are high, and appear to have improved since 2003. Despite this high level of awareness, an increased reported past use of POEC and a generally positive attitude to future use of POEC, very few of the women had taken POEC during this pregnancy. In addition, there appears to be confusion regarding the correct time limit for effectiveness of POEC, especially amongst the 16-20-year-old age group. Rather worryingly, this area of knowledge regarding the time limit for effectiveness of POEC appears to have decreased since 2003, especially among 16-20-year-olds.

These results suggest that public awareness campaigns have been effective in increasing awareness of POEC and its availability. More emphasis is needed on raising pregnancy risk awareness and an understanding of the appropriate and effective use of POEC. Efforts in this area especially need to be targeted at the 16-20-year-old age group, since this group has the poorest level of knowledge and is at high risk for unplanned pregnancy.

Statements on funding and competing interests

Funding None identified.

Competing interests None identified.

\section{References}

1 Mathew S, Urquhart R. Awareness of emergency contraception. J Fam Plann Reprod Health Care 2005; 31: 113-114.

2 Gordon AF, Owen P. Emergency contraception: change in knowledge of women attending for termination of pregnancy from 1984 to 1996. Br J Fam Plann 1999; 24: 121-122.

3 Office for National Statistics. Number of Emergency Contraceptives Prescribed, 1990 to 2000: Social Trends 33. http://www.statistics.gov.uk/STATBASE/ssdataset.asp?vlnk=64 23\&More $=Y$ [Accessed 3 November 2006].

4 WHO Task Force on Postovulatory Methods of Fertility Regulation. Randomised controlled trial of levonorgestrel versus the Yuzpe regimen of combined oral contraceptives for emergency contraception. Lancet 1998; 352: 428-433.

$5 \mathrm{Hu}$ X, Cheng L, Hua X, Glasier A. Advanced provision of emergency contraception to postnatal women in China makes no difference to abortion rates. A randomised controlled trial. Contraception 2005; 72: 111-116.

6 Glasier A, Fairhurst K, Wyke S, Ziebland S, Seaman P, Walker $\mathrm{J}$, et al. Advanced provision of emergency contraception has not reduced abortion rates in Lothian. Contraception 2004; 69 : 361-366.
The Cervix (2nd edn). J Jordan and A Singer (eds). Oxford, UK: Blackwell Publishing Ltd, 2006. ISBN: 1-40513-137-7. Price: $£ 160.00$. Pages: 637 (hardback)

This weighty, authoritative book is the complete textbook of the cervix, 'in health and disease'.

Starting from basic structure and function, through development, it provides the latest understanding of the cervix in fertility, infertility, pregnancy and labour. There is a section on cervical infections and the extensive final sections cover all aspects of cervical neoplasia.

Throughout, this text is well supported with fabulous clinical photographs and microscope slides. Each chapter brings in the latest research and is extensively referenced.

The list of editors and contributors includes many distinguished experts in this field from around the world.

As a jobbing colposcopist I found this book a joyous reminder of the shear beauty of this amazing little organ - as well as its vulnerabilities. Medical undergraduates could certainly dip into this book, while for researchers in the field it will be a bible. In fact most professionals in reproductive health care would find this a valuable reference book for understanding clinical problems involving the cervix.

Reviewed by Kate Weaver, MFSRH Staff Grade in Reproductive Health Care, Edinburgh, UK
The Sex Book. S Godson, M Agace. London, UK: Cassell Illustrated, 2006. ISBN: 1-84403511-5. Price: £9.99. Pages: 288 (paperback)

This is one of my favourite books to recommend to clients who attend for sex therapy or those seeking advice about improving their sex lives. Those who may have read Suzi Godson's columns in The Independent on Sunday or in Body and Soul will be aware of her unique style and appreciate how very special this book really is.

The cover, layout and pictures truly bring this book into the 21 st century! The topics are covered in a practical, no-nonsense, fun way with quotes from real people who have experienced or not experienced the various aspects being discussed. For clients seeking general information about sexual matters it is the perfect reference book. I love the modern, colourful illustrations. They are clear and due to their unique style cross boundaries of colour, creed race, gender and sexual orientation. There is less emphasis on the touchy, feely, emotional an 'therapy' aspects of sex that are commonly associated with books about improving sex lives I feel this enhances the book's appeal to both men and women. The bright pink cover demands that it be noticed - not just by the person who picks it up to read but by anybody else around.

It is divided into six sections with relevan chapters: The Body (for men and women, also includes understanding the sensuous side of it), Solo Sex (masturbation for men and women), Sex (including methods, positions, techniques, definitions), Sexploration (dealing with fantasy and other sexual practices), Sex Lives (dealing with sexuality, contraception, sex toys, ageing and illness) and Sexual Health (including STIs, HIV and AIDS). The chapter on contraception needs updating but in general provides excellent information. Throughout the book there is a neat two-step warning system. Wherever there is a yellow flag in the margin, it implies that there are health or safety implications and the reader can go straight to the information page indicated. If an activity carries more serious risks then the flag is red. The emphasis is on enjoying sex but certainly always being safe too! The directory and reading list at the end are also very helpful, although future editions will probably have greatly expanded versions of these two listings.

I love many things about this book, not least the frank and sensitive way in which sexual techniques, attitudes and styles are represented. As Professor Robert Winston says in his foreword to this book, it signals a change in attitudes towards sexuality and deserves the widest possible readership. I cannot recommend this book enough as a truly wonderful addition to anyone's book collection - both to read and to recommend to clients.

Reviewed by Neelima Deshpande, MRCOG, Dip PST

Staff Grade Doctor in Family Planning and Psychosexual Therapist, Heart of Birmingham Teaching Primary Care Trust (HoBtPCT), Birmingham, UK 